\title{
A New Hybrid Approach for Wind Speed Prediction Using Fast Block Least Mean Square Algorithm and Artificial Neural Network
}

\author{
Ummuhan Basaran Filik \\ Department of Electrical and Electronics Engineering, Anadolu University, Eskisehir, Turkey \\ Correspondence should be addressed to Ummuhan Basaran Filik; ubasaran@anadolu.edu.tr
}

Received 13 April 2016; Revised 4 September 2016; Accepted 15 September 2016

Academic Editor: Alessandro Mauro

Copyright (C) 2016 Ummuhan Basaran Filik. This is an open access article distributed under the Creative Commons Attribution License, which permits unrestricted use, distribution, and reproduction in any medium, provided the original work is properly cited.

\begin{abstract}
A new hybrid wind speed prediction approach, which uses fast block least mean square (FBLMS) algorithm and artificial neural network (ANN) method, is proposed. FBLMS is an adaptive algorithm which has reduced complexity with a very fast convergence rate. A hybrid approach is proposed which uses two powerful methods: FBLMS and ANN method. In order to show the efficiency and accuracy of the proposed approach, seven-year real hourly collected wind speed data sets belonging to Turkish State Meteorological Service of Bozcaada and Eskisehir regions are used. Two different ANN structures are used to compare with this approach. The first six-year data is handled as a train set; the remaining one-year hourly data is handled as test data. Mean absolute error (MAE) and root mean square error (RMSE) are used for performance evaluations. It is shown for various cases that the performance of the new hybrid approach gives better results than the different conventional ANN structure.
\end{abstract}

\section{Introduction}

Recently the alternative renewable and clean energy sources have gained great importance in the world. Principally the wind and solar energy sources have received much attention because of their minimal environmental effect and sustainability [1-3]. Wind energy is one of the most economical methods for electrical energy generation. On the other hand, wind power plants require continuous and appropriate intensity winds. In terms of the reliability and power quality of the power systems, the variability of wind power has led to problems. To minimize these problems, highly accurate wind speed prediction method should be used $[1,4]$ for optimum grid operations.

Wind speed prediction can be considered as three categories based on the prediction horizon [4]:

(i) Immediate short term prediction is usually applied to intervals ranging from 10 secs to 8 hours ahead and used generally in electricity market-wind prediction control. (ii) Short term prediction is usually for 8 hours to 168 hours ahead; it has attracted the attention of most researchers because of strategy planning and commitment decisions of systems.

(iii) Long term prediction is for ranges that are one week longer used generally in maintenance planning and wind farm study.

Immediate and short term wind speed prediction are critical and challenging problems for optimum grid operations. Various methods have been implemented in the last decades, such as regression-based methods [5-9], ANN models [1015], Markov chains [16-21], support vector regression [22, 23], and spatiotemporal models [24], and recently, applications of hybrid ANNs-hybrid models with statistical or other intelligent [25-38] approaches have received attentions.

In this study, a new hybrid approach which is based on FBLMS and ANN is proposed for short term wind speed prediction. Since adaptive FBLMS algorithm operates on an instantaneous basis, the weighting vector is updated for every 
new iteration. The adaptation of filter parameters is performed in the frequency domain using fast and efficient Fast Fourier Transform (FFT) algorithm [39]. FBLMS algorithm has also improved convergence rate which can also easily follow seasonal or other variations in data set [40]. This powerful adaptive prediction filter is applied together with ANN to get a superior performance.

To compare the performances of the proposed FBLMS and ANN based hybrid approach with conventional and known ANN based methods, real hourly wind speed values are used. The hourly averaged wind data are collected from two different regions stations of Turkish State Meteorological Service of Eskisehir and Bozcaada.

The remaining parts of the paper are organized as follows. In Section 2, the FBLMS method with ANN and its algorithm steps for wind speed prediction are clarified briefly. In Section 3, description and representation of data used for this study Eskisehir and Bozcaada region are given. Applications of the model and prediction correctness results are presented and the results of this method are compared in the sense of MAE and RMSE in Section 4. Finally, in Section 5, the main contributions of this paper are emphasized and possible research directions are discussed.

\section{Hybrid FBLMS and ANN Method for Wind Speed Prediction}

Adaptive filters are one of the most efficient solutions when the input signal's characteristics are not available, especially for filtering and prediction problems. The most popular and very well analyzed adaptive filter algorithms implementation is the least mean squares (LMS) widely used and there are many variations of this algorithm, reducing the complexity and increasing the convergence gracious rate [40]. This algorithm instantly updates the prediction for each new sample. An important method to find the coefficients of the solution is fast block. This method is gracious, but raw computations requirement of these algorithms can be a problem for systems that need many filter taps. For performing fast convolution, FFT algorithm provides a powerful tool and fast correlation [39].

The weight vector is updated for every new sample since the algorithm operates on an instantaneous basis. But a steady-state analysis of convergence for the LMS algorithm with deterministic reference inputs showed that the steadystate weight vector is biased, and thus the adaptive estimate does not approach the Wiener solution. To solve this problem, another strategy to estimate the coefficients is the block LMS algorithm. The coefficient vector is updated only once every occurrence based on block gradient estimation in this algorithm [40].

FBLMS technique is a quick numerically efficient version of the block LMS. It will have the same characteristics with regard to adaptive performance but potentially can need much fewer operations to implement. Using the FFT algorithm with an overlap-save method, the adaptation of filter parameters is performed in the frequency domain [41]. Including overlapping output sections rather than input sections, the overlap-add method results in more computation. A schematic diagram of the FBLMS with overlap-save method is given in Figure 1. The details of the FBLMS algorithm are presented in [41].

The implementation of FBLMS algorithm can be summarized as follows.

Step 1 (filtering). Consider

$$
\bar{x}_{F}(k)=\operatorname{FFT}(\tilde{x}(n)),
$$

where $\tilde{x}(n)$ is the zero padded and extended input vector.

$y(k)$ are the last elements of inverse FFT (IFFT) of

$$
\bar{x}_{F}(k) \otimes \bar{W}_{F}(k),
$$

where $\bar{W}_{F}(k)$ is tap weight vector and $\otimes$ denotes element-byelement multiplication of vectors.

Step 2 (error estimation). Consider

$$
\bar{e}(k)=\bar{d}(k)-\bar{y}(k),
$$

where $\bar{d}(k)$ is a desired wind speed value and $\bar{y}(k)$ is an output wind speed value.

Step 3 (adaptation of tap weight). Consider

$$
\bar{e}_{F}(k)=\operatorname{FFT}\left(\left[\begin{array}{c}
0 \\
\bar{e}(k)
\end{array}\right]\right)
$$

$$
\bar{W}_{F}(k+1)=\bar{W}_{F}(k)+2 \mu(k) \otimes \bar{X}_{F}^{*}(k) \otimes{\overline{e^{*}}}_{F}(k),
$$

where $\bar{W}_{F}(k+1)$ is tap weight vector update, where $\mu$ is defined as step size.

Step 4 (constraint of tap weight). Consider

$$
\begin{aligned}
& \bar{W}_{F}(k+1) \\
& =\operatorname{FFT}\left(\left[\begin{array}{c}
\text { the first } N \text { elements of } \operatorname{IFFT}\left(\bar{W}_{F}(k+1)\right) \\
\overline{0}
\end{array}\right]\right) .
\end{aligned}
$$

Step 5. The outputs of ANN model are utilized for wind speed data.

The output of FBLMS is selected as one of the inputs of the ANN structure. Hybrid FBLMS and ANN structure for wind speed prediction structure is presented in Figure 2. In the simulations, $M$ is chosen as six which is the number of neurons.

In this figure, $y(n)$ is the output of the FBLMS method $x(n-i)$, where $i=1, \ldots, 4$ are the previous available wind speed values. The proposed ANN structure uses both the available previous wind speed hourly values and FBLMS output. A detailed diagram for the second structure is shown in Figure 3.

\section{Description and Representation of the Data Set}

In this study, six-year hourly wind speed data of Bozcaada and Eskisehir regions between 2007 and 2012 are used for 


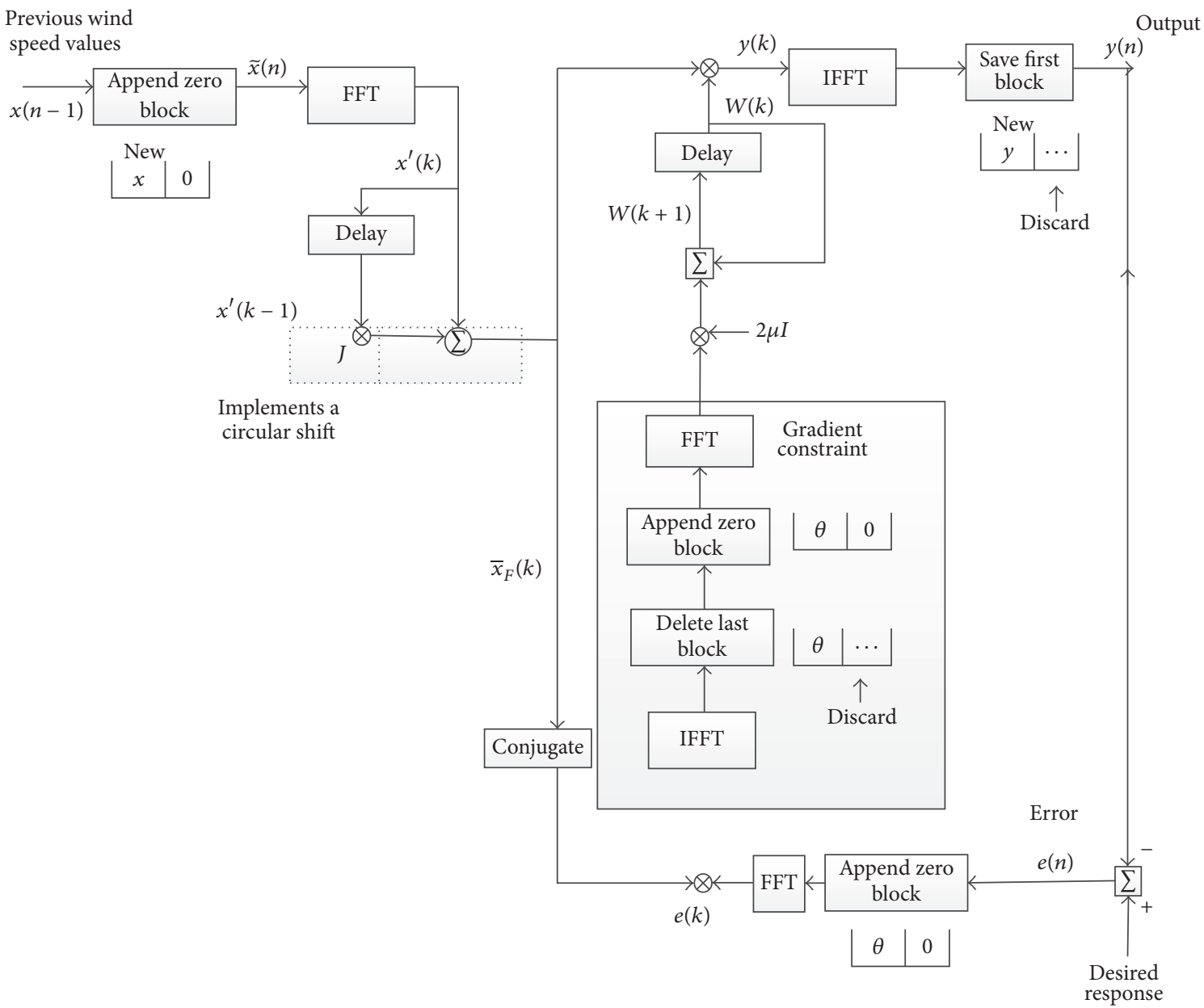

Figure 1: FBLMS overlap-save method block diagram.

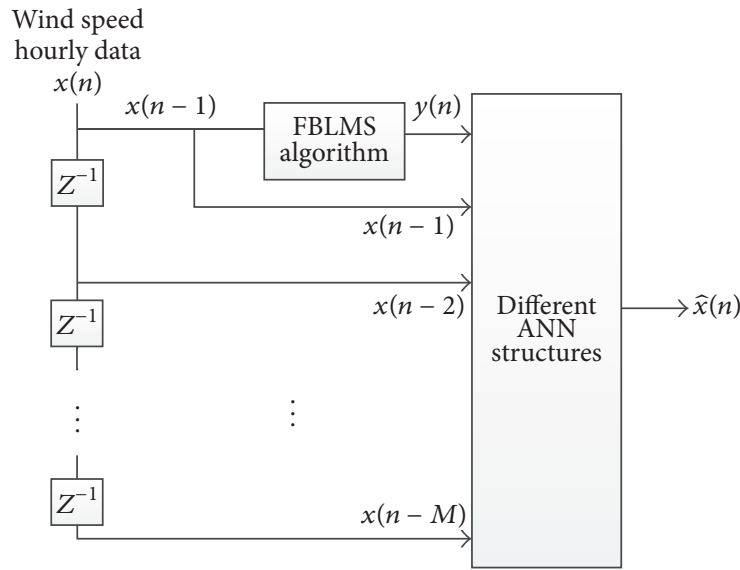

FIGURE 2: FBLMS and ANN method structure for wind speed prediction.

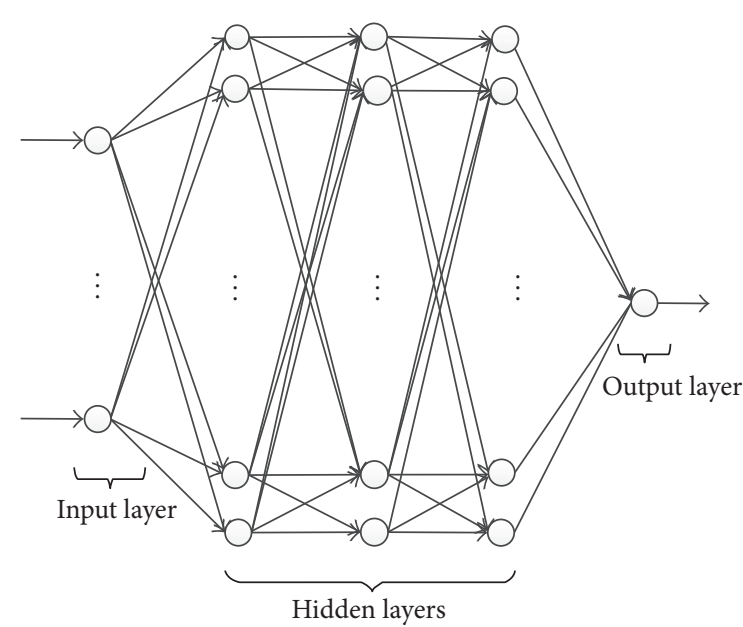

FIGURE 3: A detailed diagram for the second structure. training. Year 2013 is used to test the accuracy of the proposed hybrid FBLMS and ANN approach. To figure out the underlying dynamics of wind speed data, a proper analysis is needed. To model the wind speed data, two regions with different spectral behaviors are handled. The data referring to Bozcaada $\left(39.8^{\circ}, 26.06^{\circ}\right)$ and Eskisehir $\left(39.7^{\circ}, 30.5^{\circ}\right)$ are used testing the proposed approach. 


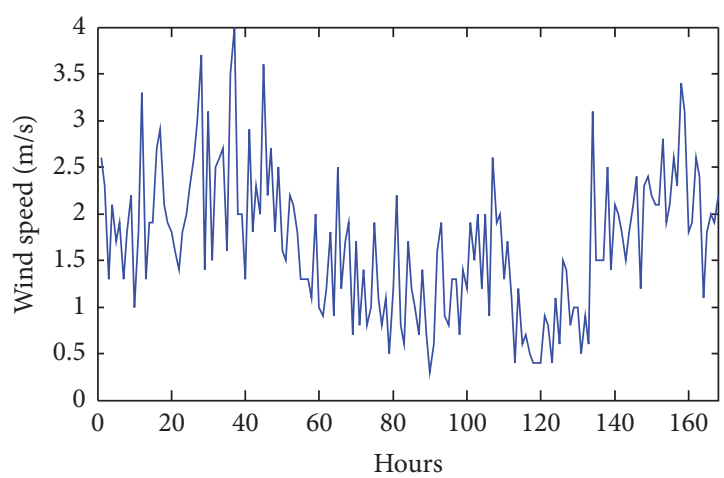

(a)

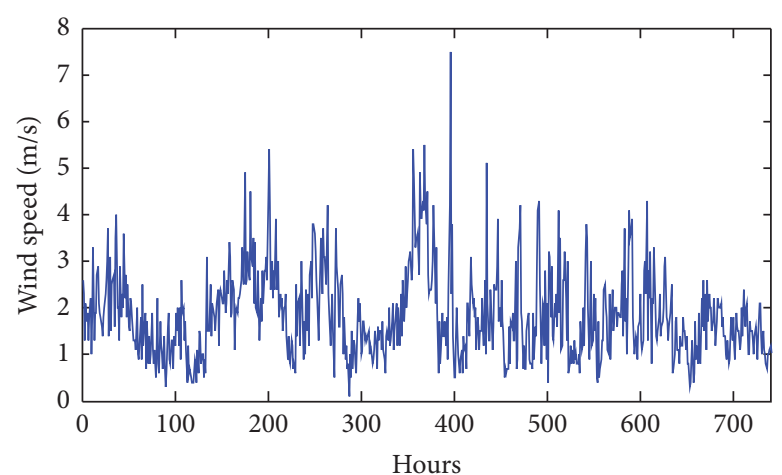

(b)

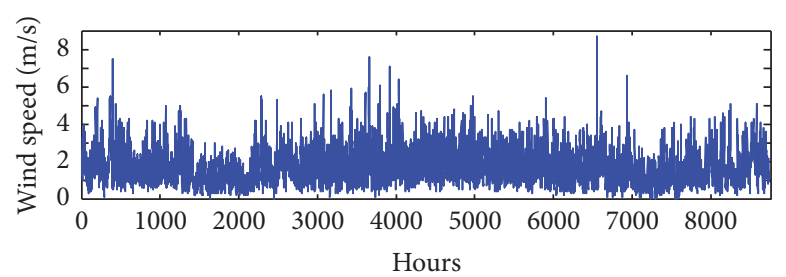

(c)

FIGURE 4: (a) Weekly pattern, (b) monthly pattern, and (c) yearly pattern of wind speed hourly data for Eskisehir in the year 2013.

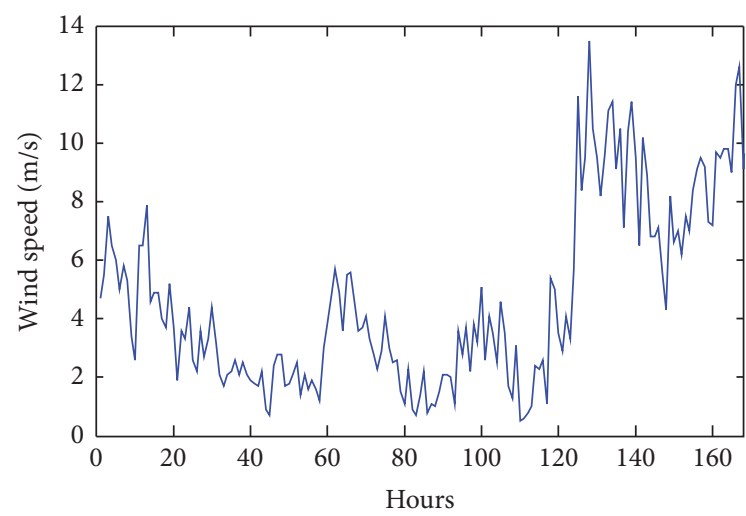

(a)

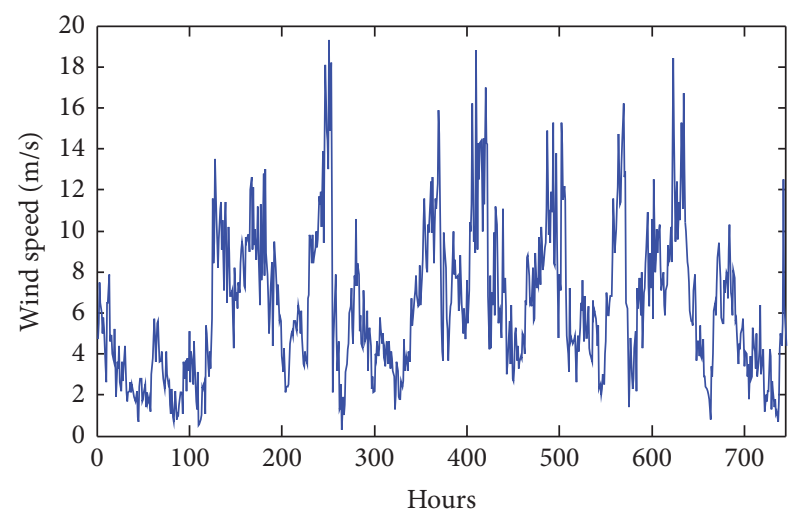

(b)

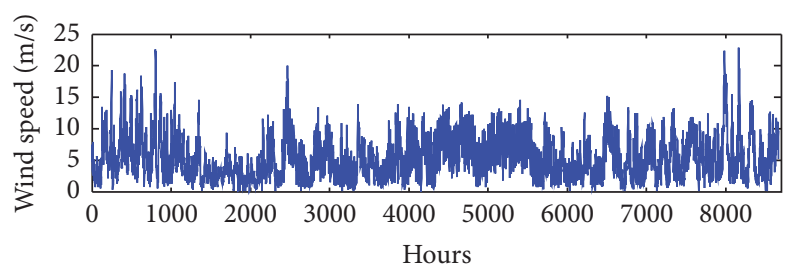

(c)

FIGURE 5: (a) Weekly pattern, (b) monthly pattern, and (c) yearly pattern of wind speed hourly data for Bozcaada in the year 2013.

Bozcaada is located in the west of Turkey and is surrounded on all sides and has a vast coastal area. Bozcaada has one of the highest wind energy potentials in Turkey. On the other hand, Eskisehir has very low wind potential due to its terrestrial climate and terrain structure. Wind speed hourly averaged data are collected from measured from Turkish
State Meteorological Service for Eskisehir region in the year 2013: (a) weekly pattern, (b) monthly pattern, and (c) yearly pattern are given in Figure 4. In Figure 5, (a) weekly pattern, (b) monthly pattern, and (c) yearly pattern of wind speed hourly averaged data are shown for Bozcaada region in the year 2013. 
TABLE 1: Some important basic statistics between 2007 and 2013 of Eskisehir and Bozcaada regions.

\begin{tabular}{|c|c|c|c|c|c|c|}
\hline \multirow{3}{*}{ Year } & \multicolumn{6}{|c|}{ Region } \\
\hline & \multicolumn{3}{|c|}{ Eskisehir (m/s) } & \multicolumn{3}{|c|}{ Bozcaada (m/s) } \\
\hline & Max & Var & Mean & Max & Var & Mean \\
\hline 2007 & 7 & 0.77 & 1.655 & 22.10 & 11.62 & 5.64 \\
\hline 2008 & 8.4 & 0.90 & 1.739 & 27.70 & 13.4 & 5.75 \\
\hline 2009 & 8.4 & 0.89 & 1.725 & 22.80 & 12.93 & 5.63 \\
\hline 2010 & 11.5 & 1.43 & 2.01 & 39.70 & 20.80 & 6.11 \\
\hline 2011 & 8.8 & 0.73 & 1.72 & 24.10 & 12.94 & 6.16 \\
\hline 2012 & 9.4 & 0.96 & 1.80 & 21.00 & 12.36 & 5.93 \\
\hline 2013 & 8.7 & 0.82 & 1.68 & 22.90 & 10.79 & 5.32 \\
\hline
\end{tabular}

As seen from Figures 4 and 5, the characteristics of wind data can be modelled as nonstationary random time series and predicting the future value is challenging problem. Magnitude of the wind speed data of two regions tell us that the wind energy potential of Bozcaada region is quite higher than Eskisehir. These two regions are especially chosen to compare the effectiveness of the method for different cases.

The important statistics of Eskisehir and Bozcaada are given in Table 1.

\section{Application and Results}

In this section, the accuracy of the proposed method is tested using wind speed data values between 2007 and 2012 for training and the remaining one-year hourly data as testing. This section of the study has been divided into three parts. In the first part, two different conventional ANN structures are applied to Eskisehir and Bozcaada wind speed data for prediction models. In the second part, hybrid FBLMS and ANN is implemented for chosen regions. In the last part, comparison of the results is discussed. The RMSE is defined as

$$
\mathrm{RMSE}=\left[\frac{1}{N} \sum_{i=1}^{N}\left(x-\widehat{x}_{i}\right)^{2}\right]^{1 / 2},
$$

where $x$ and $\widehat{x}_{i}$ are the exact and predicted wind speed values, respectively.

The MAE can be defined as

$$
\mathrm{MAE}=\frac{1}{N} \sum_{t=1}^{n}\left|x-\widehat{x}_{i}\right|,
$$

where $N$ is the number of periods of time.

4.1. Conventional ANN Structures for Wind Speed Prediction. The different conventional ANN structures have been commonly used to predict wind speed values $[1,5,8,9]$. To make fair comparison, the ANN structures are created where the previous available past values are used as in Figure 2. The hourly parameters of wind speed data are got as the input; the hourly prediction values are got as the output values. Two different ANN structures are applied. The first ANN structure has two layers as shown in Figure 2. Feed forward backpropagation is handled as a network type. The second ANN

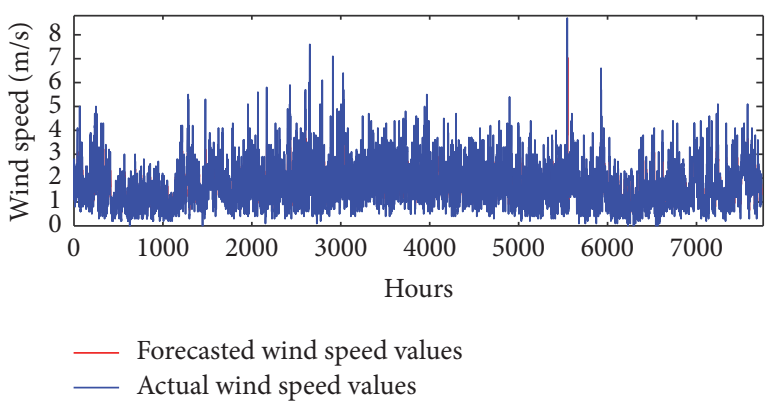

(a)

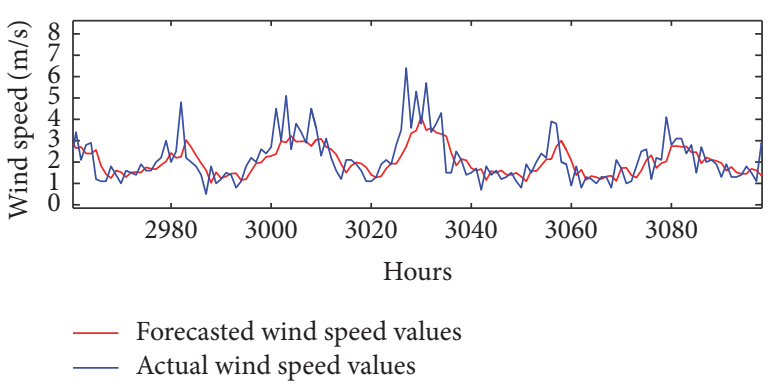

(b)

FIgURE 6: (a) Actual wind speed and output values of the first ANN structure for Eskisehir results in the year 2013 (b) and a zoomed portion of the results $(\mathrm{MAE}=0.5189, \mathrm{RMSE}=0.6880)$.

structure consists of five layers and three of them are hidden layers. Each hidden layer has ten neurons. The number of neurons of input layer is six and output layer has one for the first and second structure. Transfer function is taken in logsigmoid. Levenberg-Marquardt backpropagation algorithm which has fast convergence is handled by learning process for all ANN structures. The trained data network structure is used for one-hour ahead prediction. Actual wind speed values and output of the first conventional ANN structure for Eskisehir results in 2013 and a zoomed portion are given in Figures 6(a) and 6(b), respectively.

Actual wind speed values and output of second ANN structure prediction results for Eskisehir region in the year 2013 and a zoomed portion are given in Figures 7(a) and 7(b), respectively. 
TABLE 2: MAE and RMSE for conventional ANN and hybrid FBLMS and ANN.

\begin{tabular}{lcccccccc}
\hline & \multicolumn{4}{c}{ Eskisehir } & \multicolumn{3}{c}{ Bozcaada } \\
& \multicolumn{2}{c}{ First structure } & \multicolumn{2}{c}{ Second structure } & \multicolumn{2}{c}{ First structure } & \multicolumn{2}{c}{ Second structure } \\
& MAE & RMSE & MAE & RMSE & MAE & RMSE & MAE & RMSE \\
\hline Conventional ANN method & 0.5189 & 0.6880 & 0.5082 & 0.6831 & 1.1972 & 1.6224 & 1.1948 & 1.6237 \\
Hybrid FBLMS and ANN method & 0.5048 & 0.6681 & 0.498 & 0.6681 & 1.1576 & 1.579 & 1.1671 & 1.594 \\
\hline
\end{tabular}

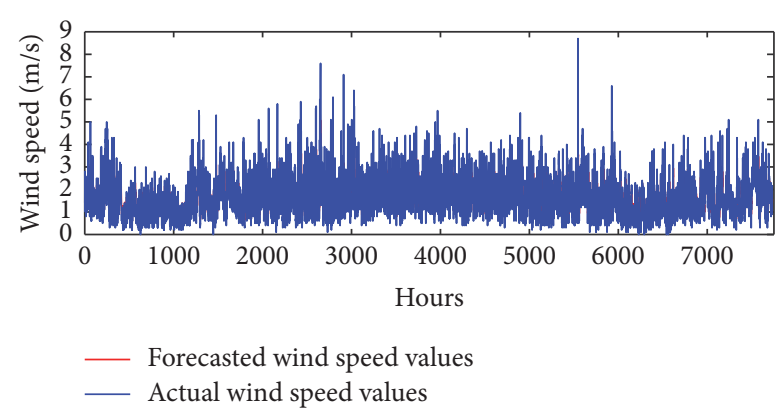

(a)

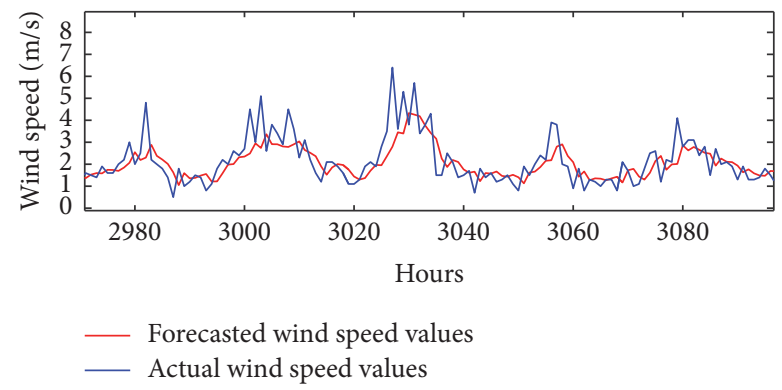

(b)

FIgURE 7: (a) Actual wind speed values and output of second ANN structure for Eskisehir results in the year 2013 (b) and a zoomed portion of the results (MAE $=0.5082$, RMSE $=0.6831$ ).

Same conventional ANN structures are also applied to Bozcaada region data. Two different structures are used as in Eskisehir. Transfer function is taken in log-sigmoid.

Actual wind speed values and output of first ANN structure for Bozcaada results in the year 2013 and a zoomed portion are given in Figures 8(a) and 8(b), respectively.

Actual wind speed values and output of second ANN structure for Bozcaada results in the year 2013 and a zoomed portion are given in Figures 9(a) and 9(b), respectively.

\subsection{Hybrid FBLMS and ANN Based Wind Speed Prediction.} FBLMS structure in Figure 1 and ANN structures are used together to make highly accurate wind speed prediction as shown in Figure 2. To our knowledge, this hybrid adaptive and ANN structure is firstly applied to wind speed prediction in this study. The real data which are collected from two different regions between 2007 and 2012 are used to train and determine the parameters of the FBLMS and ANN structures. Then the wind speed data of Eskisehir and Bozcaada region for the year 2013 are used to test the performance of the proposed structures.

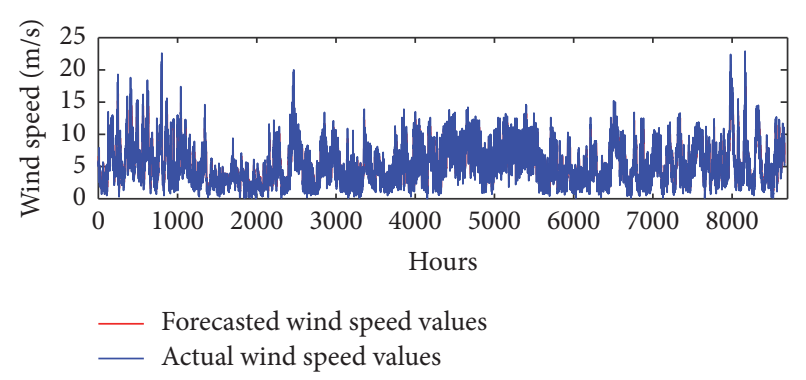

(a)

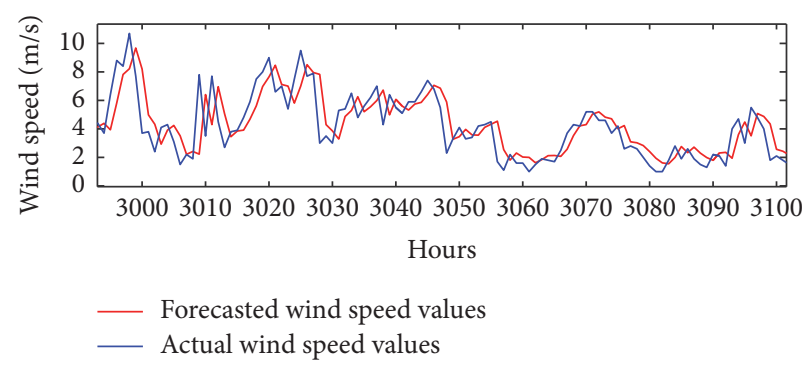

(b)

Figure 8: (a) Actual wind speed values and first ANN structure for Bozcaada results in the year 2013 (b) and a zoomed portion of the results $(\mathrm{MAE}=1.1972$, $\mathrm{RMSE}=1.6224)$.

Actual wind speed values and output of hybrid FBLMS and ANN method for first structure in Eskisehir results in the year 2013 and a zoomed portion are given in Figures 10(a) and $10(\mathrm{~b})$, respectively.

Actual wind speed values and output of hybrid FBLMS and ANN method for second structure in Eskisehir results in the year 2013 and a zoomed portion are given in Figures 11(a) and $11(\mathrm{~b})$, respectively.

Actual wind speed values and output of hybrid FBLMS and ANN method for first structure in Bozcaada results in the year 2013 and a zoomed portion are given in Figures 12(a) and $12(\mathrm{~b})$, respectively.

Actual wind speed values and output of hybrid FBLMS and ANN method for second structure in Bozcaada results in the year 2013 and a zoomed portion are given in Figures $13(\mathrm{a})$ and $13(\mathrm{~b})$, respectively.

4.3. Comparison of the Results of Conventional ANN and Hybrid FBLMS and ANN Method. MAE and RMSE results for conventional ANN and hybrid FBLMS and ANN method is presented in Table 2 .

MAE and RMSE values in Table 2 are calculated using (6) and (7), respectively. Since the mean values are smaller 


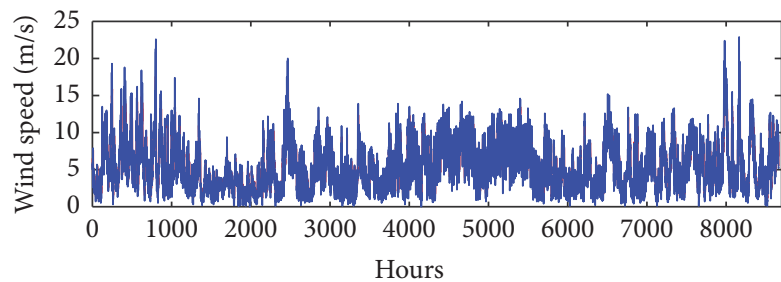

_ Forecasted wind speed values

_ Actual wind speed values

(a)

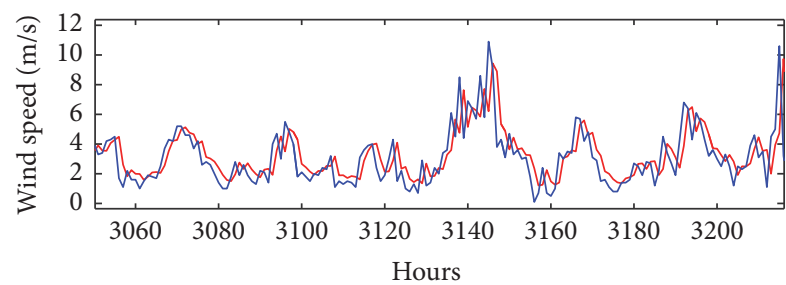

_ Forecasted wind speed values _ Actual wind speed values

(b)

FIgURE 9: (a) Actual wind speed values and second ANN structure for Bozcaada results in the year 2013 (b) and a zoomed portion of the results $(\mathrm{MAE}=1.1948, \mathrm{RMSE}=1.6237)$.

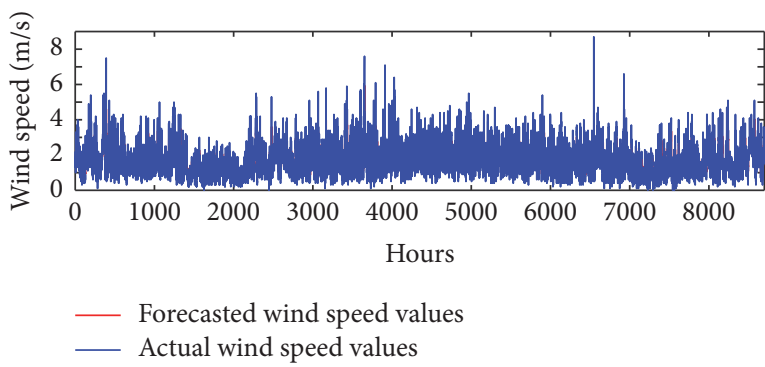

(a)

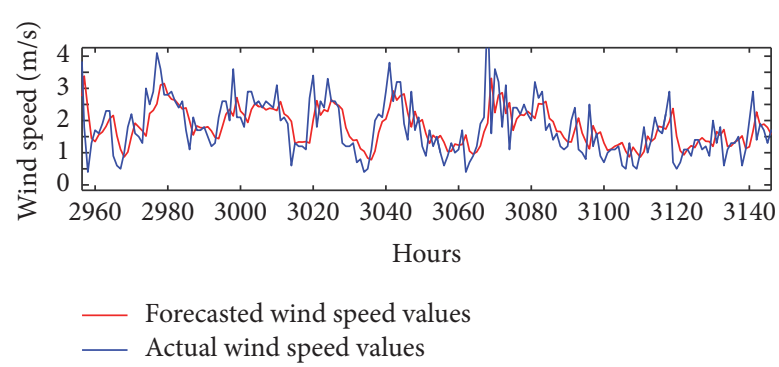

(b)

FIGURE 10: (a) Actual wind speed values and output of the hybrid FBLMS and ANN method for first structure in Eskisehir results in the year 2013 (b) and a zoomed portion of the results $($ MAE $=0.5048$, RMSE $=0.6681$.

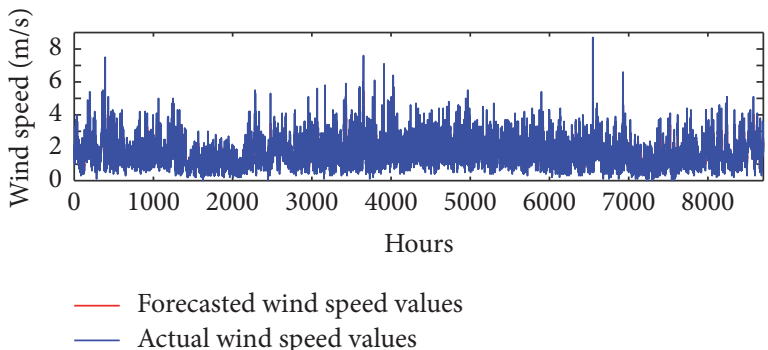

(a)

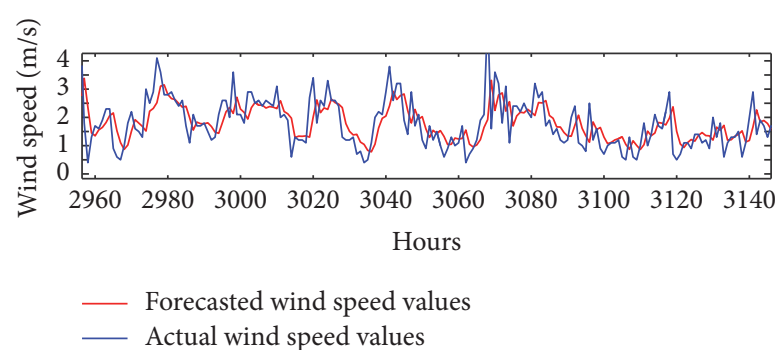

(b)

FIGURE 11: (a) Actual wind speed values and output of the hybrid FBLMS and ANN method for second structure in Eskisehir results in the year 2013 (b) and a zoomed portion of the results (MAE $=0.498$, RMSE $=0.6681$ ).

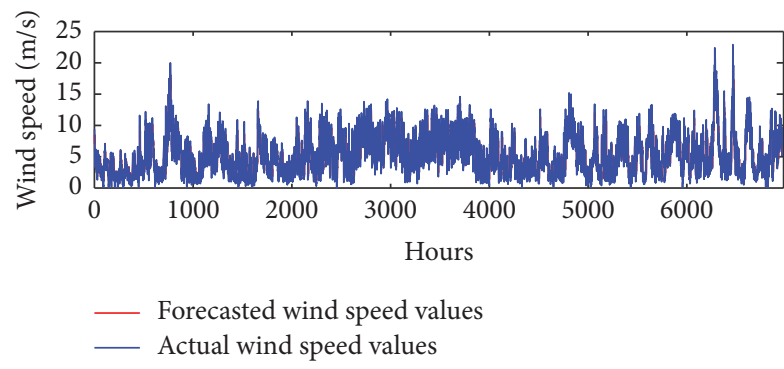

(a)

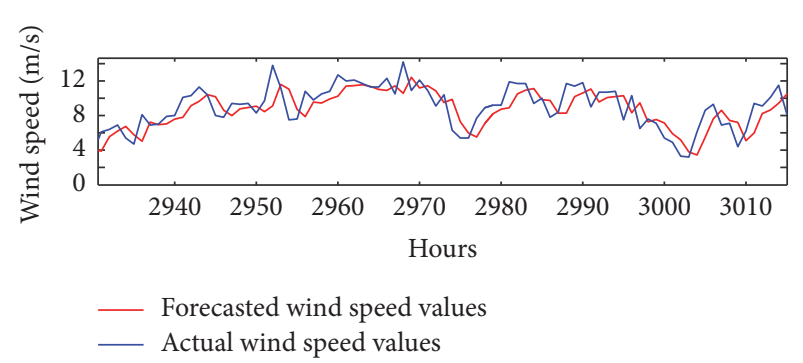

(b)

FIGURE 12: (a) Actual wind speed values and output of the hybrid FBLMS and ANN method for first structure in Bozcaada results in the year 2013 (b) and a zoomed portion of the results (MAE $=1.1576$, RMSE $=1.579$ ). 


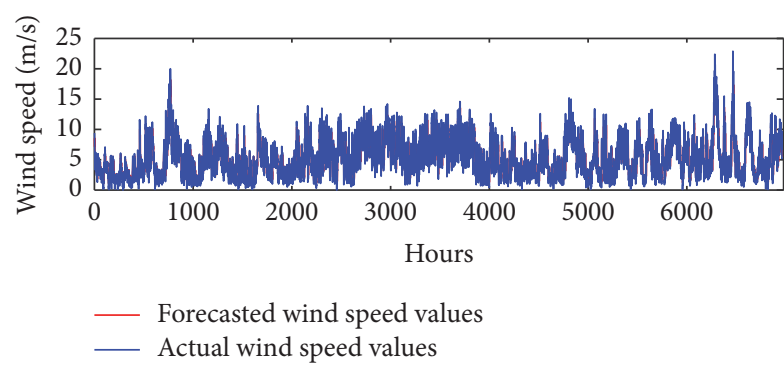

(a)

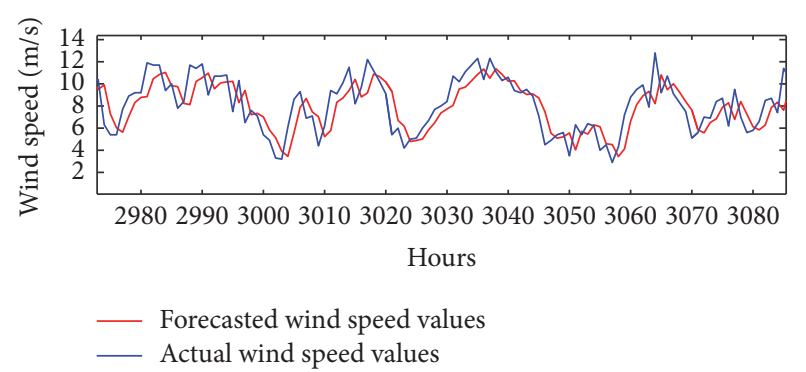

(b)

FIGURE 13: (a) Actual wind speed values and output of the hybrid FBLMS and ANN method for second structure in Bozcaada results in years 2013 (b) a zoomed portion of the results $(\mathrm{MAE}=1.1671$, RMSE $=1.594)$.

in Eskisehir region, the error values of Eskisehir are lower than Bozcaada region. On the other hand, hybrid FBLMS and ANN method finds best results of selected two regions. The error values are approximately decreased between $2.1 \%$ and $3.3 \%$ when the proposed approach is applied.

\section{Conclusion}

Prediction of the wind speed values is quite significant for optimum electricity market operations, strategy planning, commitment decision, and wind farms studies for all horizon. Although wind speed data has some diurnal and seasonal periodicities, it is highly stochastic data and it is hard to predict future values. In this study, hybrid FBLMS and ANN method is firstly used to predict wind speed values to get more accurate results. Since, the proposed approach is based on adaptive filtering, the seasonal and other variations on data can be successfully tracked which reduces the overall error. To make fair comparison, ANN structure with two and five layers and the proposed hybrid FBLMS and ANN method are applied to real wind data. Consequently, the proposed hybrid FBLMS+ANN method's performance is better than the conventional ANN approximately between 2.1\% and $3.3 \%$. Additionally, this approach is fast and can adaptively track the variations on data.

\section{Abbreviations}

$\begin{array}{ll}\bar{W}_{F}(k+1): & \text { Tap weight vector update } \\ \tilde{x}(k): & \text { Extended input vector } \\ \bar{d}(k): & \text { Desired output vector } \\ \bar{W}_{F}(k): & \text { Tap weight vector } \\ y(k): & \text { The last elements of IFFT of } \bar{x}_{F}(k) \otimes \bar{W}_{F}(k) \\ N: & \text { Filter length } \\ L: & \text { Block length } \\ \mu: & \text { Step size } \\ x: & \text { Data } \\ Z^{-1}: & \text { One sample delay. }\end{array}$

\section{Competing Interests}

The author declares that there are no competing interests.

\section{Acknowledgments}

This work was supported by Anadolu University Scientific Research Projects Fund with Project no. 1505F512. The received fund covers the costs to publish in open access. And the author is grateful to the Turkish State Meteorological Service for providing the data.

\section{References}

[1] M. A. Duran and Ü. Başaran Filik, "Short-term wind speed prediction using several artificial neural network approaches in Eskisehir," in Proceedings of the International Symposium on Innovations in Intelligent Systems and Applications (INISTA '15), pp. 1-4, Madrid, Spain, September 2015.

[2] Ü. Başaran Filik and M. Kurban, "Potential analysis of some renewable energy sources for Eskisehir, Turkey," in Proceedings of the World Renewable Energy Congress X (WREC X '08), Glasgow, UK, July 2008.

[3] Ü. Basaran Filik, T. Filik, and O. N. Gerek, "New electric transmission systems: experiences from Turkey," in Handbook of Clean Energy Systems, J. Yan, Ed., John Wiley \& Sons, New York, NY, USA, 2015.

[4] Ü. Başaran Filik, "Wind speed prediction based on different artificial neural network approach for Eskisehir region," in Proceedings of the 5th International 100\% Renewable Energy Conference (IRENEC '15), Istanbul, Turkey, 2015.

[5] J. L. Torres, A. García, M. De Blas, and A. De Francisco, "Forecast of hourly average wind speed with ARMA models in Navarre (Spain)," Solar Energy, vol. 79, no. 1, pp. 65-77, 2005.

[6] R. G. Kavasseri and K. Seetharaman, "Day-ahead wind speed forecasting using f-ARIMA models," Renewable Energy, vol. 34, no. 5, pp. 1388-1393, 2009.

[7] E. Erdem and J. Shi, "ARMA based approaches for forecasting the tuple of wind speed and direction," Applied Energy, vol. 88, no. 4, pp. 1405-1414, 2011.

[8] S. Chun, J. Quan, and F. Yequn, "Correlation analysis for wind speed and failure rate of wind turbines using time series approach," Journal of Renewable and Sustainable Energy, vol. 4, no. 3, Article ID 032301, 2012.

[9] B. Hassen, "A fast and accurate model for forecasting wind speed and solar radiation time series based on extreme learning machines and principal components analysis," Journal of Renewable and Sustainable Energy, vol. 6, no. 1, Article ID 013114, 2014. 
[10] E. Cadenas and W. Rivera, "Wind speed forecasting in three different regions of Mexico, using a hybrid ARIMA-ANN model," Renewable Energy, vol. 35, no. 12, pp. 2732-2738, 2010.

[11] M. C. Mabel and E. Fernández, "Analysis of wind power generation and prediction using ANN: a case study," Renewable Energy, vol. 33, no. 5, pp. 986-992, 2008.

[12] H. Liu, H.-Q. Tian, and Y.-F. Li, "Comparison of two new ARIMA-ANN and ARIMA-Kalman hybrid methods for wind speed prediction," Applied Energy, vol. 98, pp. 415-424, 2012.

[13] J. Ping, G. Yingjie, and W. Chen, "Research and application of a hybrid forecasting model based on simulated annealing algorithm: A Case Study of Wind Speed Forecasting," Journal of Renewable and Sustainable Energy, vol. 8, no. 1, Article ID 015501, 2016.

[14] S. R. Nandha Kishore and V. Vanitha, "Wind speed forecasting for grid code compliance," Journal of Renewable and Sustainable Energy, vol. 5, Article ID 063125, 2013.

[15] J. Wang, Q. Zhou, H. Jiang, and R. Hou, "Short-term wind speed forecasting using support vector regression optimized by cuckoo optimization algorithm," Mathematical Problems in Engineering, vol. 2015, Article ID 619178, 13 pages, 2015.

[16] G. D'Amico, F. Petroni, and F. Prattico, "First and second order semi-Markov chains for wind speed modeling," Physica A: Statistical Mechanics and Its Applications, vol. 392, no. 5, pp. 1194-1201, 2013.

[17] M. Yoder, A. S. Hering, W. C. Navidi, and K. Larson, "Shortterm forecasting of categorical changes in wind power with Markov chain models," Wind Energy, vol. 17, no. 9, pp. 14251439, 2014.

[18] S. P. Evans and P. D. Clausen, "Modelling of turbulent wind flow using the embedded Markov chain method," Renewable Energy, vol. 81, pp. 671-678, 2015.

[19] R. Carapellucci and L. Giordano, "A new approach for synthetically generating wind speeds: a comparison with the Markov chains method," Energy, vol. 49, no. 1, pp. 298-305, 2013.

[20] Z. Song, Y. Jiang, and Z. Zhang, "Short-term wind speed forecasting with Markov-switching model," Applied Energy, vol. 130, pp. 103-112, 2014.

[21] X. Chen, S. Jin, S. Qin, and L. Li, "Short-term wind speed forecasting study and its application using a hybrid model optimized by cuckoo search," Mathematical Problems in Engineering, vol. 2015, Article ID 608597, 18 pages, 2015.

[22] Q. Hu, S. Zhang, M. Yu, and Z. Xie, "Short-term wind speed or power forecasting with heteroscedastic support vector regression," IEEE Transactions on Sustainable Energy, vol. 7, no. 1, pp. 241-249, 2016.

[23] P. Ailliot and V. Monbet, "Markov-switching autoregressive models for wind time series," Environmental Modelling \& Software, vol. 30, pp. 92-101, 2012.

[24] T. Filik, "Improved spatio-temporal linear models for very short-term wind speed forecasting," Energies, vol. 9, no. 3, article 168, 2016.

[25] E. Zhao, J. Zhao, L. Liu, Z. Su, and N. An, "Hybrid wind speed prediction based on a self-adaptive ARIMAX model with an exogenous WRF simulation," Energies, vol. 9, no. 1, article 7, 2016.

[26] E. Cadenas and W. Rivera, "Wind speed forecasting in three different regions of Mexico, using a hybrid ARIMA-ANN model," Renewable Energy, vol. 35, no. 12, pp. 2732-2738, 2010.

[27] Z.-H. Guo, J. Wu, H.-Y. Lu, and J.-Z. Wang, "A case study on a hybrid wind speed forecasting method using BP neural network," Knowledge-Based Systems, vol. 24, no. 7, pp. 10481056, 2011.

[28] Y. Zhang, J. Yang, K. Wang, and Y. Wang, "Lorenz wind disturbance model based on grey generated components," Energies, vol. 7, no. 11, pp. 7178-7193, 2014.

[29] H. Liu, H.-Q. Tian, C. Chen, and Y.-F. Li, "A hybrid statistical method to predict wind speed and wind power," Renewable Energy, vol. 35, no. 8, pp. 1857-1861, 2010.

[30] W. Zhang, J. Wang, W. Z. Zengbao, and M. Tian, "Short-term wind speed forecasting based on a hybrid model," Applied Soft Computing, vol. 13, no. 7, pp. 3225-3233, 2013.

[31] J. Shi, J. Guo, and S. Zheng, "Evaluation of hybrid forecasting approaches for wind speed and power generation time series," Renewable and Sustainable Energy Reviews, vol. 16, no. 5, pp. 3471-3480, 2012.

[32] W.-Y. Chang, "Short-term wind power forecasting using the enhanced particle swarm optimization based hybrid method," Energies, vol. 6, no. 9, pp. 4879-4896, 2013.

[33] Z. Guo, J. Zhao, W. Zhang, and J. Wang, "A corrected hybrid approach for wind speed prediction in Hexi Corridor of China," Energy, vol. 36, no. 3, pp. 1668-1679, 2011.

[34] H. Liu, C. Chen, H.-Q. Tian, and Y.-F. Li, "A hybrid model for wind speed prediction using empirical mode decomposition and artificial neural networks," Renewable Energy, vol. 48, pp. 545-556, 2012.

[35] J. Wang, J. Hu, K. Ma, and Y. Zhang, "A self-adaptive hybrid approach for wind speed forecasting," Renewable Energy, vol. 78, pp. 374-385, 2015.

[36] M. Niu, S. Sun, J. Wu, and Y. Zhang, "Short-term wind speed hybrid forecasting model based on bias correcting study and its application," Mathematical Problems in Engineering, vol. 2015, Article ID 351354, 13 pages, 2015.

[37] V. Ranganayaki and S. N. Deepa, "An intelligent ensemble neural network model for wind speed prediction in renewable energy systems," The Scientific World Journal, vol. 2016, Article ID 9293529, 14 pages, 2016.

[38] A. E. Saleh, M. S. Moustafa, K. M. Abo-Al-Ez, and A. A. Abdullah, "A hybrid neuro-fuzzy power prediction system for wind energy generation," International Journal of Electrical Power \& Energy Systems, vol. 74, pp. 384-395, 2016.

[39] S. Haykin, Adaptive Filter Theory, chapter 10, 3rd edition, 1996.

[40] S. Olmos, L. Sörnmo, and P. Laguna, "Block adaptive filters with deterministic reference inputs for event-related signals: BLMS and BRLS," IEEE Transactions on Signal Processing, vol. 50, no. 5, pp. 1102-1112, 2002.

[41] B. Farhang-Boroujeny and K. S. Chan, "Analysis of the frequency-domain block LMS algorithm," IEEE Transactions on Signal Processing, vol. 48, no. 8, pp. 2332-2342, 2000. 


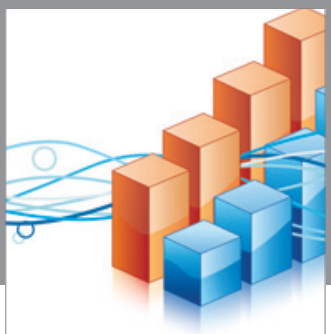

Advances in

Operations Research

vatem alat4

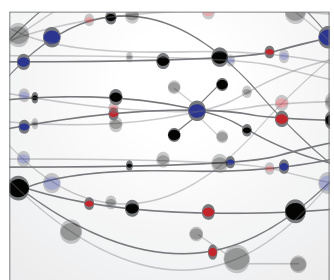

\section{The Scientific} World Journal
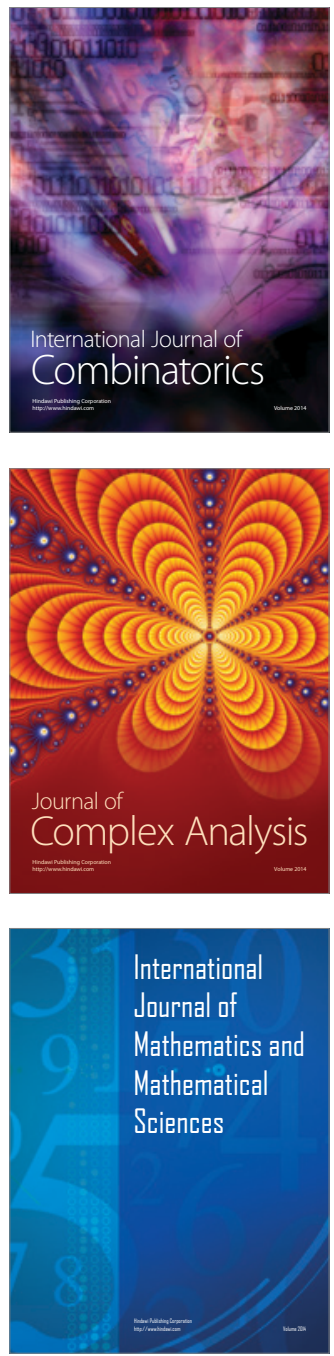
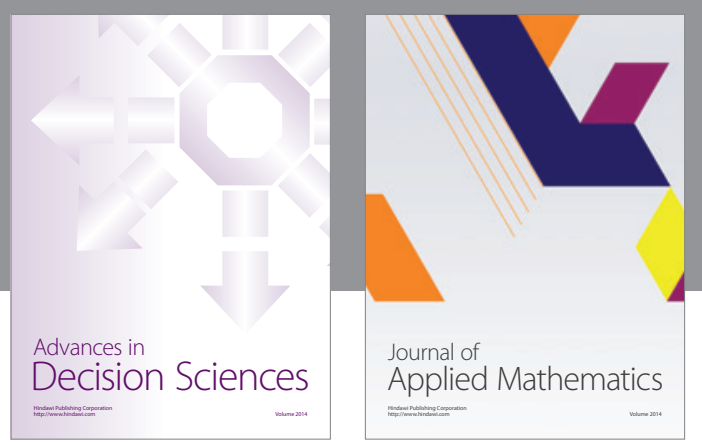

Algebra

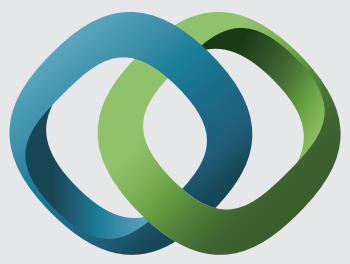

\section{Hindawi}

Submit your manuscripts at

http://www.hindawi.com
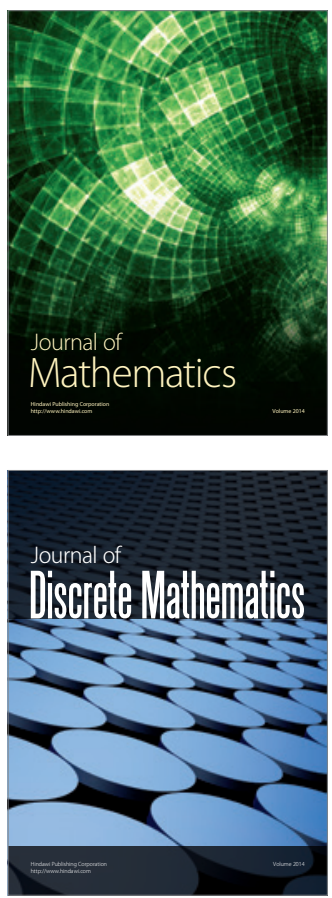

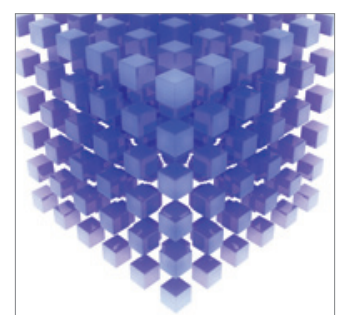

Mathematical Problems in Engineering
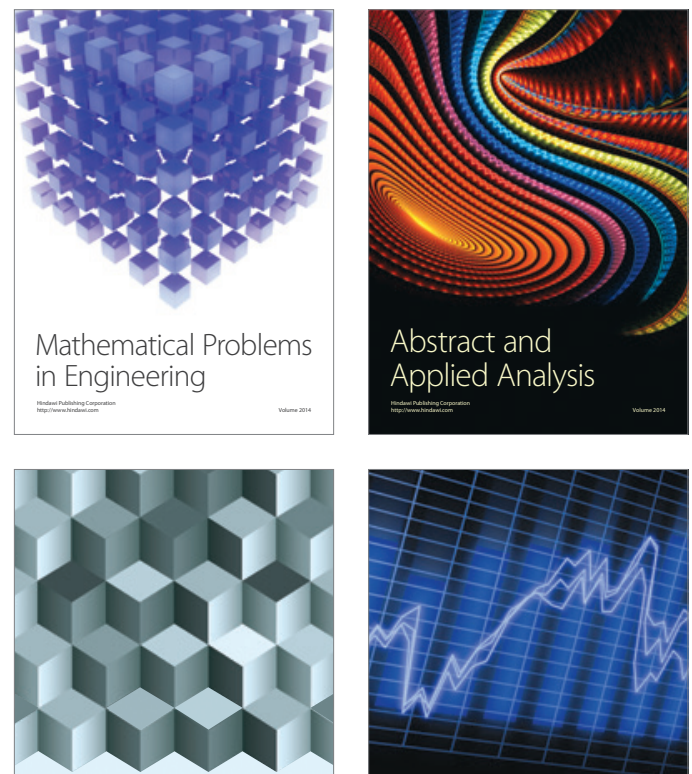

Journal of

Function Spaces

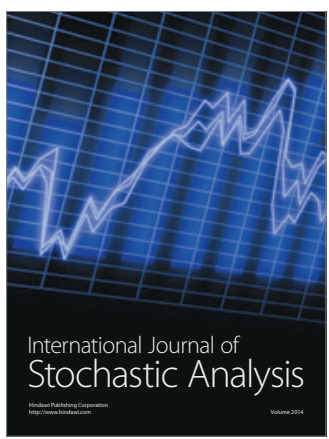

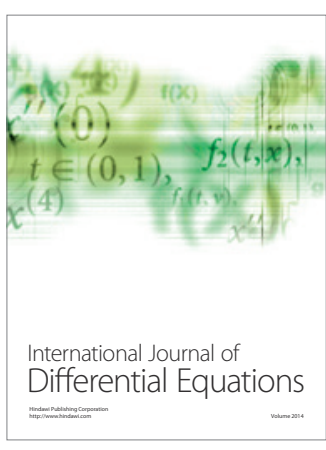
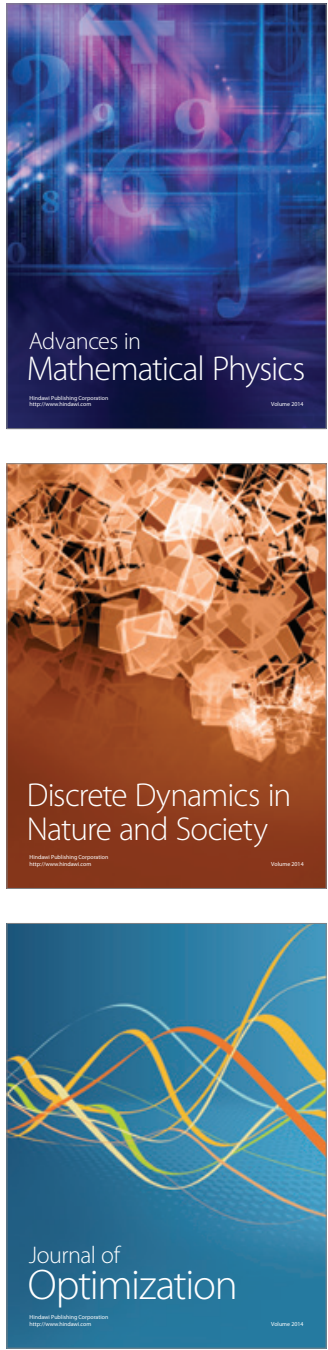